\title{
Establishment of inducible cAMP early repressor transgenic fibroblasts in a porcine model of human type 1 diabetes mellitus
}

\author{
EUI-MAN JUNG ${ }^{1}$, YU-KYUNG KIM ${ }^{2}$, GEUN-SHIK LEE ${ }^{3}$, SANG-HWAN HYUN $^{4}$, \\ WOO-SUK HWANG ${ }^{2}$ and EUI-BAE JEUNG ${ }^{1}$
}

\author{
${ }^{1}$ Laboratory of Veterinary Biochemistry and Molecular Biology, College of Veterinary Medicine, \\ Chungbuk National University, Cheongju, Chungbuk 361-763; ${ }^{2}$ SooAm Biotech Research Foundation, Seoul 137-851; \\ ${ }^{3}$ Laboratory of Veterinary Physiology, College of Veterinary Medicine, Kangwon National University, \\ Chuncheon, Gangwon 200-701; ${ }^{4}$ Laboratory of Veterinary Embryology and Biotechnology, College of Veterinary Medicine, \\ Chungbuk National University, Cheongju, Chungbuk 361-763, Republic of Korea
}

Received January 10, 2012; Accepted April 20, 2012

DOI: $10.3892 / \mathrm{mmr} .2012 .895$

\begin{abstract}
Diabetes mellitus is a metabolic disease caused by impaired insulin secretion from the pancreatic $\beta$ cells and increased insulin resistance in peripheral tissues. Recently, the overexpression of inducible cyclic AMP (cAMP) early repressor (ICER) I $\gamma$ in rodent pancreatic $\beta$ cells was found to induce insulin deficiency and glucagon overproduction similar to that found in human diabetes mellitus. ICER I $\gamma$ with only a DNA binding domain interrupts the transcriptional regulation of the cAMP responsive element-binding protein (CREB) target genes. Based on this information, we hypothesized that the overexpression of ICER I $\gamma$, the most powerful competitor to CREB, could be useful for generating a pig model of diabetes. First, we evaluated the promoter activities of the human insulin gene for the $\beta$ cell-specific overexpression of ICER I $\gamma$ in the pig pancreas. The maximum promoter activity region $[-1,431$ nucleotides (nt) to $+1 \mathrm{nt},+1=$ the transcriptional start site] of the insulin gene presented an activity level 3-fold higher than a promoterless construct. Second, ICER I $\gamma$ overexpression controlled by this promoter region significantly blocked the glucose-mediated insulin transcription, such as that regulated by the viral promoter in the pancreatic $\beta$ cell line, MIN6. This suggests that the human insulin promoter may facilitate the overexpression of ICER I $\gamma$ in porcine pancreatic $\beta$ cells.
\end{abstract}

Correspondence to: Dr Eui-Bae Jeung, Laboratory of Veterinary Biochemistry and Molecular Biology, College of Veterinary Medicine, Chungbuk National University, 12 Gaesin-dong, Cheongju, Chungbuk 361-763, Republic of Korea

E-mail: ebjeung@chungbuk.ac.kr

Dr Woo-Suk Hwang, SooAm Biotech Research Foundation, Bangbae 3 Dong, 1027-4 SooAm Building, Seoul 137-851, Republic of Korea

E-mail: hwangws@sooam.org

Key words: pig, fibroblast, diabetes mellitus, inducible cyclic AMP early repressor $\mathrm{I} \gamma$, human insulin promoter
In addition, the overexpression of ICER I $\gamma$ in porcine $\beta$ cells may induce human-like type 1 diabetes mellitus in pigs. In the present study, we generated transgenic fibroblasts containing ICER I $\gamma$ cDNA controlled by the human insulin promoter, as well as two screening markers, the green fluorescence protein and the neomycin resistance gene. These fibroblasts may provide a source for somatic cell nuclear transfer to generate a pig model that mimics human diabetes mellitus.

\section{Introduction}

Diabetes mellitus is a class of metabolic diseases in which an individual has high blood sugar either because the body does not produce enough insulin or because the pancreatic $\beta$ cells are unresponsive to insulin. There are two main types of diabetes mellitus. Type 1 diabetes mellitus (also referred to as insulin-dependent diabetes mellitus or IDDM) is characterized by the failure to produce sufficient quantities of insulin. Individuals with this form of the disease require exogenous insulin for survival. Type 2 diabetes mellitus (also referred to as non-insulin-dependent diabetes mellitus or NIDDM) is caused by defects in insulin secretion along with insulin resistance $(1,2)$.

The transcriptional regulation of the insulin genes is mediated by specific combinations of positive and negative factors through multiple $c i s$-acting elements. The insulin genes are influenced by changes in glucose or cyclic AMP (cAMP) levels (3). The cAMP response element (CRE), one of the cis-acting elements, was first identified as an inducible enhancer of gene transcription (4). CRE is capable of activating gene transcription in response to increased cAMP levels. cAMP is known to be an important determinant of gene expression in pancreatic islet cells $(5,6)$. Protein kinase A (PKA) plays a crucial role in the regulation of glycogen metabolism and activation of cAMP production. Additionally, this factor is involved in a number of diverse signaling pathways. High levels of cAMP activate PKA, which then phosphorylates the CRE-binding protein (CREB). CREB is known to stimulate insulin gene transcription by binding to the CRE in the promoter of the insulin gene $(7,8)$. 
The CREB gene also generates repressors to reduce the cAMP-induced transcription by alternative splicing (9). Inducible cAMP early repressor (ICER I $\gamma$ ), one of the repressors, is generated from an alternative intronic promoter on the CREB gene. ICER I $\gamma$ that competes with CREB reduces the cAMP-induced transcription (10). It has been shown that the ICER I $\gamma$ overexpression in $\beta$ cells increases the incidence of diabetes mellitus in a rodent model, as the overexpressed ICER I $\gamma$ competes with endogenous CRE-binding activators to block CRE-mediated transcription in pancreatic $\beta$ cells $(11,12)$. In addition, the overexpression of ICER I $\gamma$ leads to decreased numbers of $\beta$ cells in transgenic mice $(13,14)$.

The mechanisms underlying diabetes mellitus are complex and not entirely understood. Therefore, the mechanisms have been widely studied using in vitro and in vivo methods. The majority of in vivo experiments have been carried out in rodents, although some studies have been performed on larger animals $(15,16)$. However, the phenotypic characteristics of this disease in rodent models do not thoroughly reflect the mechanisms of human diabetes. Thus, in the present study, we produced porcine transgenic fibroblasts that were genetically modified to induce type 1 diabetes mellitus-like symptoms in a porcine model. This was accomplished by overexpressing ICER I $\gamma$ in porcine $\beta$ cells. These cells may provide a source for somatic cell nuclear transfer methods used to generate an animal model of diabetes.

\section{Materials and methods}

Cell culturing. Unless otherwise indicated, all cells were grown at $37^{\circ} \mathrm{C}$ and all cell culture materials were obtained from Invitrogen (Carlsbad, CA, USA). Porcine fibroblasts were obtained from miniature pig fetuses (Yucatan pigs, Optifarm Solution Inc., Gyeonggi-do, Korea) on the 30th day of pregnancy, and the mouse $\beta$ cell line, MIN6 (ATCC, Manassas, VA), was cultured in Dulbecco's modified Eagle's medium (DMEM) containing 10\% fetal bovine serum (FBS; Welgene, Daejeon, South Korea), $50 \mathrm{U} / \mathrm{ml}$ penicillin and $50 \mu \mathrm{g} / \mathrm{ml}$ streptomycin in a humidified $5 \% \mathrm{CO}_{2}$ atmosphere.

Genomic DNA extraction and PCR. Genomic DNA from the cells was isolated with a G-DEX ${ }^{\mathrm{TM}}$ IIc Genomic DNA Extraction kit (iNtRON Biotechnology, Seoul, South Korea). Genomic DNA $(1 \mu \mathrm{g})$ was amplified in a $20-\mu 1$ PCR reaction containing 1 U LA-Taq polymerase (Takara, Otsu, Shiga, Japan) for long-range PCR, or $1 \mathrm{U}$ i-Start Taq polymerase (iNtRON) for the other PCR reaction, 2 mM dNTPs (Takara) and $10 \mathrm{pmol}$ of each specific primer. The detail of all primers are described in Table I. The PCR reactions were denatured at $95^{\circ} \mathrm{C}$ for $30 \mathrm{sec}$, annealed at $62^{\circ} \mathrm{C}$ for $30 \mathrm{sec}$, and extended at $72^{\circ} \mathrm{C}$ for 1 or $2 \mathrm{~min}$. The PCR products were subjected to cloning processes and/or separated on a $0.7 \%$ agarose gel, stained with ethidium bromide and photographed under UV illumination. The image was scanned using GelDoc EQ (Bio-Rad, Hercules, CA, USA).

RNA preparation and semi-quantitative PCR. Total RNA from MIN6 cells or pig pancreas was extracted using TRIzol reagent (Invitrogen) according to the manufacturer's instructions. The concentration of the total RNA was determined by measuring the absorbance at $260 \mathrm{~nm}$. First-strand cDNA was prepared by subjecting total RNA $(1 \mu \mathrm{g})$ to reverse transcription using mMLV reverse transcriptase (Invitrogen) and random primers (9-mers; Takara). To determine the optimal conditions for logarithmic phase PCR amplification for target cDNA, aliquots of total cDNA $(1 \mu \mathrm{g})$ were amplified using different numbers of cycles. The cytochrome $\mathrm{c}$ oxidase subunit $1(1 \mathrm{~A})$ gene was amplified as the internal control to rule out the possibility of RNA degradation and to control for variations in mRNA concentrations. A linear relationship between PCR product band visibility and the number of amplification cycles was observed for the target mRNA. The $1 \mathrm{~A}$ and insulin target genes were quantified using 28 and 30 cycles, respectively. The PCR reactions were denatured at $95^{\circ} \mathrm{C}$ for $30 \mathrm{sec}$, annealed at $58^{\circ} \mathrm{C}$ for $30 \mathrm{sec}$, and extended at $72^{\circ} \mathrm{C}$ for $30 \mathrm{sec}$. The PCR products were on a $2.3 \%$ agarose gel, stained with ethidium bromide and photographed under UV illumination. The image was scanned and the band density was analyzed using GelDoc EQ and its software (Bio-Rad).

Vector construction. All restriction enzymes were obtained from Takara. Various regions of the human insulin promoter [from nucleotides (nt) $-1,873$ to $+1 \mathrm{nt},+1=$ the transcriptional start site] were prepared by long-range PCR using human genomic DNA (Clontech Mountain View, CA, USA) as the template and specific primers containing restriction enzyme sites (MluI at the $5^{\prime}$ end or $\mathrm{XhoI}$ at the $3^{\prime}$ end). Amplified fragments were digested with $M l u \mathrm{I}$ and $\mathrm{XhoI}$ and ligated into the promoterless luciferase expression plasmid, pGL3-Basic (Promega, Madison, WI, USA). The ICER I $\gamma$ expression cassette plasmid was produced in several steps. ICER I $\gamma$ cDNA was prepared by PCR using cDNA from pig pancreas as the template. Amplified fragments were inserted into pcDNA3.1 (Invitrogen) or ligated into the recombinant pGL3 construct containing the human insulin promoter region $(-1,431 \mathrm{nt}$ to +1 $n t)$. For the selection cassettes, the enhanced green fluorescent protein (EGFP) gene was amplified from pIRES2-EGFP (Clontech), digested with EcoRV and BamHI, and inserted into the pIRES-Neo plasmid (Clontech). Both the EGFP and neomycin resistance gene $\left(\mathrm{Neo}^{\mathrm{r}}\right)$ were further amplified by PCR, digested with SalI, and ligated into the recombinant pGL3 vector encoding porcine ICER I $\gamma$ cDNA controlled by the human insulin promoter. Finally, the sequences of the targeting vector were confirmed by nucleotide sequencing (Genotech Co. Ltd., Daejeon, Korea).

Transient transfection and reporter gene assay. Transient transfection was carried out using Lipofectamine ${ }^{\mathrm{TM}} 2000$ (Invitrogen) according to the manufacturer's instructions. To control for different transfection efficiencies of the various luciferase constructs, the Rous sarcoma virus (RSV)-lacZ plasmid was co-transfected into the MIN6 cells with luciferase constructs containing the insulin promoter $(17,18)$. Briefly, $3 \times 10^{5}$ cells were seeded in 6 -well tissue culture plates 1 day prior to transfection. In total, $4 \mu \mathrm{g}$ of the constructs containing the insulin promoter and $0.5 \mu \mathrm{g}$ of RSV-lacZ plasmid were co-transfected into the cells under serum-free DMEM. After incubating for $4 \mathrm{~h}$, the medium was replaced with DMEM containing $10 \%$ FBS and glucose $(0.1 \mathrm{mM}$ or $4 \mathrm{mM})$ for an additional $48 \mathrm{~h}$. Cellular lysates were assayed for luciferase activity 
Table I. Primer sequences.

\begin{tabular}{|c|c|c|c|}
\hline Name & Restriction enzyme & Direction & Sequences $\left(5^{\prime}\right.$ to $\left.-3^{\prime}\right)$ \\
\hline Human insulin promoter $(-1,873)$ & MluI & Forward & ACG CGT CTC AAG GAG GCA CCC A \\
\hline Human insulin promoter $(-1,432)$ & MluI & Forward & ACG CGT GTA CCC CAG GGG CTC AG \\
\hline Human insulin promoter $(-482)$ & MluI & Forward & ACG CGT CTG GCC ACC GGG CC \\
\hline Human insulin promoter $(+1)$ & XhoI & Reverse & CTC GAG GGC CAG CAG CGC CAG \\
\hline ICER I $\gamma$ cDNA & NcoI & Forward & CCA TGG ATG GCT GTA ACT GGA GAT GAA ACA G \\
\hline ICER I $\gamma$ cDNA & $X b a \mathrm{I}$ & Reverse & TCT AGA CTA ATC TGT TTT AGG AGA GCAAAT GTC \\
\hline EGFP cDNA & EcoRV & Forward & GAT ATC CAC AAC CAT GGT GAG CAA GGG CGA \\
\hline EGFP cDNA & BamHI & Reverse & GGA TCC TTA CTT GTA CAG CTC GTC CAT GCC \\
\hline Confirming primer $a$ & & Forward & CCA GGA CAG GCT GCA TCA GA \\
\hline Confirming primer $b$ & & Reverse & GCA ACC CGA CTC TCC AGA CA \\
\hline Confirming primer $c$ & & Forward & CAT GAA GCA GCA CGA CTT CT \\
\hline Confirming primer $d$ & & Reverse & CCT AGG AAT GCT CGT CAA GA \\
\hline $1 \mathrm{~A}$ & & Forward & CCA GGA TTT GGA ATT ATT TC \\
\hline $1 \mathrm{~A}$ & & Reverse & GAA AAT AAA GCC TAA GGC TC \\
\hline Insulin & & Forward & CCC TGT TGG TGC ACT TCC TA \\
\hline Insulin & & Reverse & CAC TTG TGG GTC CTC CAC TT \\
\hline
\end{tabular}

EGFP, enhanced green fluorescent protein.

using the Luciferase Assay System (Promega). Luminescence was measured using a GloMax 20/20 Luminometer (Promega). $\beta$-galactosidase activity was measured using a $\beta$-galactosidase Enzyme Assay System (Promega). The relative luciferase activity was calculated as luciferase activity/ $\beta$-galactosidase activity (\%).

Establishment of transgenic cell lines. The fibroblasts were then transfected with the linearized targeting vector using Lipofectamine 2000. After $24 \mathrm{~h}$ of transfection, the medium was replaced with DMEM supplemented with 10\% FBS and $250 \mu \mathrm{g} / \mathrm{ml} \mathrm{G}-418$ (Roche, Indianapolis, IN, USA) for 4 weeks. The antibiotic-resistant colonies were further selected according to EGFP expression observed with a fluorescence microscope (Nikon, Tokyo, Japan). The antibiotic and visually selected colonies were subjected to PCR-based genotyping and stored until required for somatic cell nuclear transfer.

Data analysis. Data are presented as the means \pm standard error of the mean (SEM). A statistical analysis was performed using the Student's t-test, with two-pair comparisons. $\mathrm{P}<0.05$ was considered to indicate a statistically significant difference.

\section{Results}

Human insulin promoter activities in the mouse $\beta$ cell lines. To determine the promoter region of the human insulin gene which would generate the maximum activity for tissue-specific expression, we generated a series of promoter variants containing different deletions of the upstream human insulin promoter region from $-1,873 \mathrm{nt}$ to $+1 \mathrm{nt}$ using human genomic DNA. The fragments were linked to the luciferase (Luc) gene in a promoterless pGL3-basic vector. These insulin promoter constructs were finally introduced into the mouse $\beta$ cell line,
MIN6, and the relative promoter activities were measured. As shown in Fig. 1, the promoter region (-1432 nt to $+1 \mathrm{nt})$ resulted in a level of activity 3 -fold higher than that of the promoterless construct. Notably, the region from $-1,431$ nt to -482 nt may contain certain enhancing elements, while a different region $(-1,872 \mathrm{nt}$ to $-1,431 \mathrm{nt})$ may possess inhibitory factor-binding sites. Thus, the region containing $-1,431$ nt to +1 nt was considered the best candidate for a $\beta$ cell-specific expression promoter.

Effect of porcine ICER I $\gamma$ overexpression on insulin production in mouse $\beta$ cells. The overexpression of ICER I $\gamma$ has previously been found to significantly repress insulin expression in a rodent model $(12,13)$; however, it is unclear whether porcine ICER I $\gamma$ can inhibit insulin transcription. We therefore isolated porcine ICER I $\gamma$ cDNA that was sub-cloned into overexpression vectors regulated by the cytomegalovirus (CMV) promoter as a positive control or by the human insulin promoter $(-1,432 \mathrm{nt}$ to $+1 \mathrm{nt})$. The production of insulin mRNA was evaluated after transiently transfecting the mouse $\beta$ cell line, MIN6, with the two constructs (Fig. 2). Wild-type MIN6 cells showed significantly upregulated insulin transcription following treatment with $4 \mathrm{mM}$ glucose. This increased level of transcription was significantly attenuated by the overexpression of porcine ICER I $\gamma$ under the control of the CMV or insulin promoter. Thus, our results indicate that porcine ICRE I $\gamma$ overexpression effectively inhibits insulin production in the $\beta$ cells.

Establishment of fibroblast cell lines that overexpress ICRE I $\gamma$. Our targeting vector contained ICER I $\gamma$ cDNA under the control of the human insulin promoter and two selection markers, EGFP and the $\mathrm{Neo}^{\mathrm{r}}$ (Fig. 3A). This vector was linearized and used to transfect miniature pig fibroblasts using a liposomalmediated gene delivery system. The transfected fibroblasts were selected with medium containing G-418 for four weeks, 


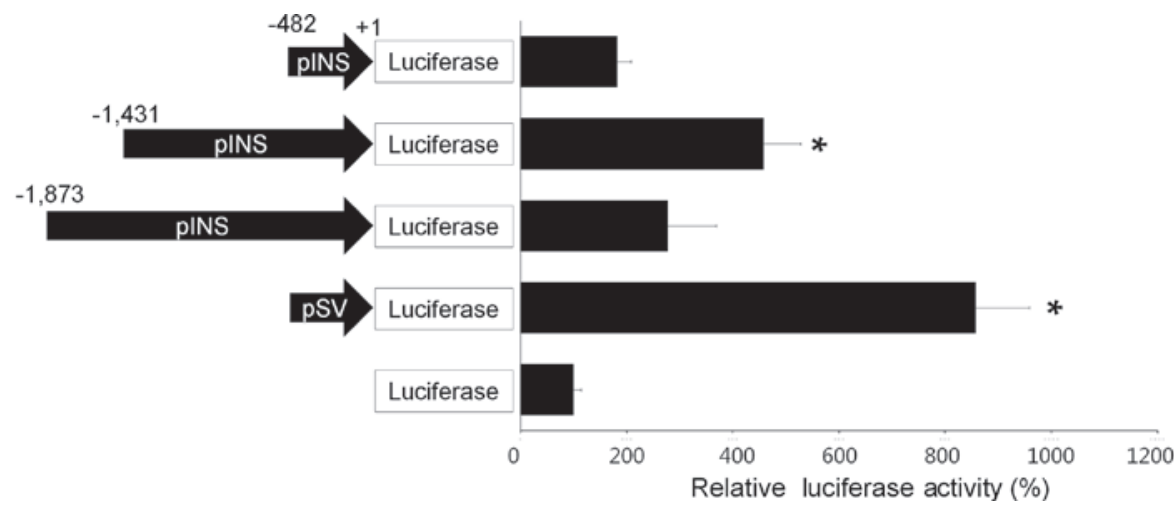

Figure 1. Promoter activities of the human insulin promoter constructs. A set of deletion constructs containing the indicated regions of the human insulin promoter (pINS) was transiently transfected into a mouse $\beta$ cell line. An RSV-lacZ expression vector was co-transfected to normalize transfection efficiency. Relative luciferase activity (RLU) is represented as the percentage induction after being normalized to $\beta$-galactosidase activity compared to the RLU of the promoterless, pGL3-basic plasmid, which was set as $100 \%$. Data represents the mean \pm SEM of three independent experiments, each performed in triplicate. ${ }^{*} \mathrm{P}<0.05$ versus the RLU of the promoterless plasmid. RSV, Rous sarcoma virus; $\mathrm{pSV}$, simian virus 40 promoter.


Figure 2. Effect of inducible cyclic AMP early repressor (ICER) I $\gamma$ overexpression on insulin transcription. MIN6, mouse $\beta$ cells, were transfected with a porcine ICER I $\gamma$ cDNA construct controlled by the cytomegalovirus (CMV) promoter (pCMV) or human insulin promoter $(-1,432 \mathrm{nt}$ to $+1 \mathrm{nt}$; pINS). The cells were then treated with $0.1 \mathrm{mM}$ glucose as a negative control or $4 \mathrm{mM}$ glucose to induce insulin gene transcription. Insulin mRNA expression was normalized by expression of the $1 \mathrm{~A}$ gene as an internal control. " $\mathrm{P}<0.05$ compared to cells treated with $0.1 \mathrm{mM}$ glucose; ${ }^{*} \mathrm{P}<0.05$ compared to cells treated with a high concentration of glucose (4 mM). Empty vector, pcDNA3.1 without ICER I $\gamma$ cDNA; Non, MIN6 cells without transfection; pINS, human insulin promoter.

which was further confirmed by EGFP expression observed with fluorescence microscopy (data not shown). Integration of the targeting vector into the genomic DNA was determined by PCR-based methods using primer sets specific for the vector. Genomic DNA from positive colonies was amplified with the primers $a$ and $b$ (amplicon size, 600 bp; Fig. 2B) or with the primers $c$ and $d$ (product size, $1 \mathrm{~kb}$; Fig. 2C). In total, 62 positive colonies were obtained after 32 rounds of transfection trials (Table II). This indicated that our system was associated with a relatively high transgenic efficiency $(91.9 \%$; 57 out of 62 colonies), although it produced a low number of positive colonies (1.9 colonies per transfection). Thus, our method involving dual screenings and liposome-mediated gene deliveries can reduce the number of false positive colonies during gene modification in pig fibroblasts. Finally, aliquots of the colonies confirmed to be positive $\left(0.6 \times 10^{6}\right.$ cells $)$ were frozen for somatic cell nuclear transfer.

\section{Discussion}

In the present study, we describe the generation of a pig fibroblast cell line for producing a porcine model of diabetes 
Table II. Transfection efficiencies of the pig fibroblasts.

No. of transfection trials No. of G418-resistant colonies No. of EGFP-positive colonies No. of PCR-positive colonies

\begin{tabular}{llll}
\hline 32 & 63 & 57 & 57
\end{tabular}

EGFP, enhanced green fluorescent protein.

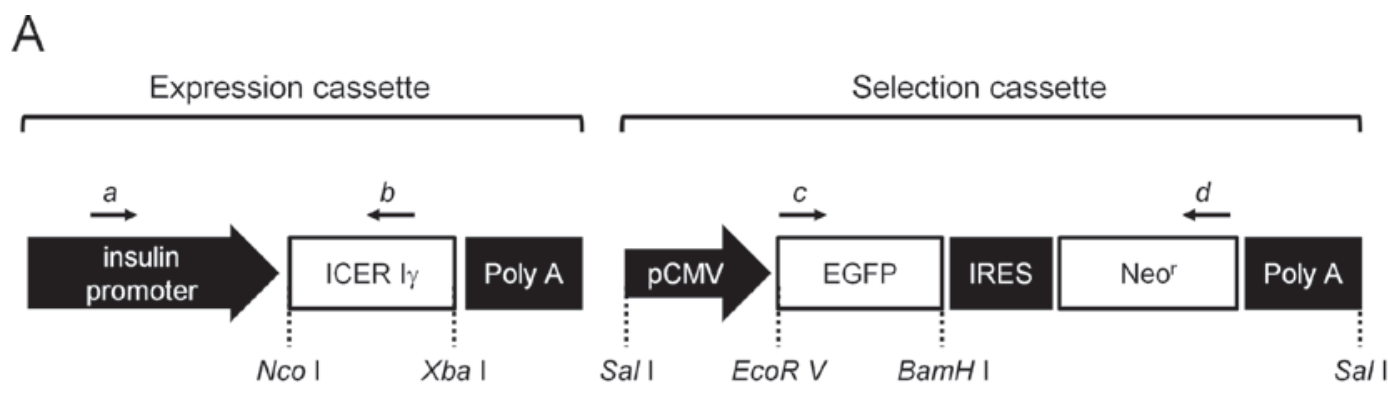

B

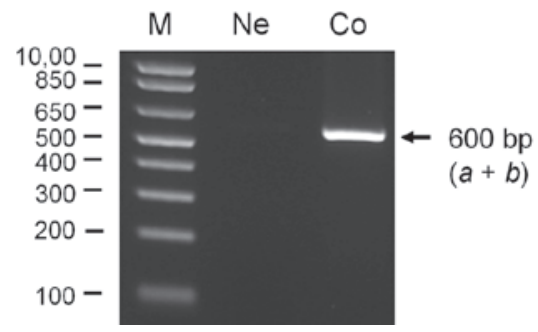

C

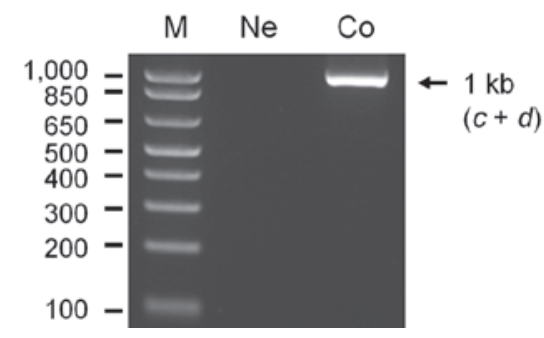

Figure 3. Schematic structure of the targeting vector and PCR-based confirmation of transgenic porcine fibroblasts. (A) The targeting vector contained expression and selection cassettes. The expression cassette included the porcine inducible cyclic AMP early repressor (ICER) I $\gamma$ gene controlled by the human insulin promoter $(-1,431 \mathrm{nt}$ to $+1 \mathrm{nt})$. The selection cassette contained the green fluorescent proteins (EGFP) and neomycin-resistance (Neo $\left.{ }^{\mathrm{r}}\right)$ genes linked by internal ribosomal entry site (IRES) sequences. ICER I $\gamma$, porcine ICER I $\gamma$ cDNA; poly A, poly A tail signaling sequences; pCMV, cytomegalovirus promoter. Integration of the targeting vectors into the genomic DNA of the fibroblasts was confirmed with specific primer sets, indicated by arrows ( $a$ to $d$ ). (B) The PCR products with primer $a$ and $b$ confirmed the chromosomal insertion of the expression cassette into the positively selected colony. (C) Transgenic fibroblasts containing the selection cassette were identified with primers $c$ and $d$. M, molecular marker; Ne, negative control without template; Co, a positively selected colony by the selection markers, EGFP and $\mathrm{NeO}^{\mathrm{r}}$.

mellitus. This established pig fibroblast cell line contained the porcine ICER I $\gamma$ gene under the control of the human insulin promoter, resulting in the downregulation of endogenous insulin production and decreased numbers of $\beta$ cells, similar to previous studies $(13,14,19)$. Two selection markers, the EGFP and $\mathrm{Neo}^{\mathrm{r}}$ genes, were useful for screening the transgenic fibroblasts and for visual identification of transgenic piglets.

$\beta$ cells in the pancreatic islets play an essential role in serum glucose homeostasis in vertebrates. These cells are capable of acting as a sensor of systemic glucose levels during the feeding state of the organism, and the transcription of genes associated with metabolism is induced by changing levels of the products of glucose catabolism; this represents specific regulation of the $\beta$ cells in response to glucose concentrations in the body $(20,21)$. The insulin promoter immediately regulates insulin gene transcription via glucose and the human promoter enables strongly regulated insulin production $(22,23)$. Based on this evidence, we focused on the insulin promoter as a $\beta$ cell-specific regulator. The current insulin promoter highly upregulated ICER I $\gamma$ gene expression in the mouse $\beta$ cell line in the presence of high glucose levels, and this upregulation effectively blocked insulin production by competing with CREB for the endogenous insulin promoter.

Components of metabolic syndrome, such as obesity, lipid abnormalities, glucose intolerance and hypertension, have long been a topic of great interest in biomedical research. One of the typical consequences of metabolic syndrome is diabetes mellitus (24-26). There are approximately 160,000 diabetics worldwide reported by the World Health Organization (WHO), and it is expected that the number of diabetic patients will double within the next 20 years (27). To further our understanding of this disease, rodent models have been extensively used due to their small size, ease of handling and short generation interval. Well-known rodent models of diabetes mellitus have been established by alloxane and a uric acid derivative resulting in insulin deficiency and hyperglycemia $(28,29)$, Additionally, streptozotocin and a nitrosurea derivative from Streptomyces achromogenes selectively destroy pancreatic $\beta$ cells, thereby inducing diabetes (30-32). The bio-breeding 
(BB) rat $(33,34)$ and non-obese diabetic (NOD) mouse $(35,36)$ both exhibit a susceptibility to the spontaneous development of autoimmune disease. Rodent models of diabetes mellitus include the genetically altered Zucker diabetic fatty (ZDF) rats $(37,38)$, Otsuka Long Evans Tokushima fatty (OLETF) rats $(39,40)$ and Goto Kakizaki $(\mathrm{GK})$ rats $(41,42)$, which feature insulin resistance and reduced $\beta$ cell number and function. Over the past decade, molecular-based techniques have produced new animal models for diabetes mellitus research including knock-in, generalized knock-out, and tissue-specific knock-out rats and mice $(15,16,43,44)$. Thus, animal models of diabetes mellitus provide crucial insight into human diabetes mellitus.

Currently established pig fibroblast cell lines should be a useful source for somatic cell nuclear transfer procedures to generate a porcine model of diabetes. These piglets will provide critical information for understanding the mechanisms underlying human type 1 diabetes mellitus. The overexpression of ICER I $\gamma$ in porcine $\beta$ cells may successfully attenuate the proliferation of $\beta$ cells and the production of insulin similar to that observed in murine models.

\section{Acknowledgements}

This study was supported by a grant from the Next-Generation BioGreen 21 Program (No. PJ008323), Rural Development Administration, Republic of Korea.

\section{References}

1. Mbanya JC and Ramiaya K: Diabetes Mellitus. In: Disease and Mortality in Sub-Saharan Africa. Jamison DT, Feachem RG, Makgoba MW, Bos ER, Baingana FK, Hofman KJ and Rogo KO (eds). World Bank, Washington, DC, pp267-287, 2006.

2. Seelandt KK: Diabetes mellitus update. J Contin Educ Nurs 38: $54-55,2007$.

3. Sander M and German MS: The beta cell transcription factors and development of the pancreas. J Mol Med (Berl) 75: 327-340, 1997.

4. Comb M, Birnberg NC, Seasholtz A, Herbert E and Goodman HM: A cyclic AMP- and phorbol ester-inducible DNA element. Nature 323: 353-356, 1986.

5. Barnett DW, Pressel DM, Chern HT, Scharp DW and Misler S: cAMP-enhancing agents "permit" stimulus-secretion coupling in canine pancreatic islet beta-cells. J Membr Biol 138: 113-120, 1994.

6. Leonard J, Serup P, Gonzalez G, Edlund T and Montminy M: The LIM family transcription factor Isl-1 requires cAMP response element binding protein to promote somatostatin expression in pancreatic islet cells. Proc Natl Acad Sci USA 89: 6247-6251, 1992.

7. Ortmeyer HK: Insulin decreases skeletal muscle cAMPdependent protein kinase (PKA) activity in normal monkeys and increases PKA activity in insulin-resistant rhesus monkeys. J Basic Clin Physiol Pharmacol 8: 223-235, 1997.

8. Seino S, Takahashi H, Fujimoto W and Shibasaki T: Roles of cAMP signalling in insulin granule exocytosis. Diabetes Obes Metab 11 Suppl 4: 180-188, 2009.

9. Laoide BM, Foulkes NS, Schlotter F and Sassone-Corsi P: The functional versatility of CREM is determined by its modular structure. EMBO J 12: 1179-1191, 1993.

10. Molina CA, Foulkes NS, Lalli E and Sassone-Corsi P: Inducibility and negative autoregulation of CREM: an alternative promoter directs the expression of ICER, an early response repressor. Cell 75: 875-886, 1993.

11. Hussain MA, Daniel PB and Habener JF: Glucagon stimulates expression of the inducible cAMP early repressor and suppresses insulin gene expression in pancreatic beta-cells. Diabetes 49: $1681-1690,2000$.
12. Inada A, Yamada Y, Someya Y, et al: Transcriptional repressors are increased in pancreatic islets of type 2 diabetic rats. Biochem Biophys Res Commun 253: 712-718, 1998.

13. Inada A, Someya Y, Yamada Y, et al: The cyclic AMP response element modulator family regulates the insulin gene transcription by interacting with transcription factor IID. J Biol Chem 274: 21095-21103, 1999.

14. Inada A, Hamamoto Y, Tsuura Y, et al: Overexpression of inducible cyclic AMP early repressor inhibits transactivation of genes and cell proliferation in pancreatic beta cells. Mol Cell Biol 24: 2831-2841, 2004.

15. Saudek F: Gene therapy in the treatment of diabetes mellitus. Cas Lek Cesk 142: 523-527, 2003 (In Czech).

16. Driver JP, Serreze DV and Chen YG: Mouse models for the study of autoimmune type 1 diabetes: a NOD to similarities and differences to human disease. Semin Immunopathol 33: 67-87, 2011.

17. Cheng CK, Hoo RL, Chow BK and Leung PC: Functional cooperation between multiple regulatory elements in the untranslated exon 1 stimulates the basal transcription of the human GnRH-II gene. Mol Endocrinol 17: 1175-1191, 2003.

18. Lee GS, Choi KC, Han HJ and Jeung EB: The classical and a non-classical pathways associated with NF-kappaB are involved in estrogen-mediated regulation of calbindin-D9k gene in rat pituitary cells. Mol Cell Endocrinol 277: 42-50, 2007.

19. Inada A, Nagai K, Arai H, et al: Establishment of a diabetic mouse model with progressive diabetic nephropathy. Am J Pathol 167: 327-336, 2005.

20. Fridlyand LE and Philipson LH: Reactive species, cellular repair and risk factors in the onset of type 2 diabetes mellitus: review and hypothesis. Curr Diabetes Rev 2: 241-259, 2006.

21. Aszalos Z: Cerebral complications of diabetes mellitus. Orv Hetil 148: 2371-2376, 2007 (In Hungarian).

22. Odagiri H, Wang $J$ and German MS: Function of the human insulin promoter in primary cultured islet cells. J Biol Chem 271: 1909-1915, 1996.

23. Burkhardt BR, Loiler SA, Anderson JA, et al: Glucose-responsive expression of the human insulin promoter in HepG2 human hepatoma cells. Ann N Y Acad Sci 1005: 237-241, 2003.

24. Nakasone H, Kako S, Endo H, et al: Diabetes mellitus is associated with high early-mortality and poor prognosis in patients with autoimmune hemolytic anemia. Hematology 14: 361-365, 2009.

25. Nosadini R, Crepaldi G and D'Angelo A: Diabetes mellitus and hypertension: a physiologic basis for a rational therapeutic approach. Am Heart J 121: 1289-1293, 1991.

26. Siraj ES, Seyoum B, Saenz C and Abdulkadir J: Lipid and lipoprotein profiles in Ethiopian patients with diabetes mellitus. Metabolism 55: 706-710, 2006.

27. Karic E, Tulumovic D, Ramic E, Zildzic M and Tulumovic A: Evaluation of diabetic nephropathy in older patients with diabetes mellitus type 2. Med Arh 62: 261-263, 2008.

28. Yargicoglu P, Agar A, Edremitlioglu M, Oguz Y and Apaydin C: The effect of cadmium on visual evoked potentials in alloxaneinduced diabetic rats: relation to lipid peroxidation. Acta Diabetol 36: 197-204, 1999

29. Rerup CC: Drugs producing diabetes through damage of the insulin secreting cells. Pharmacol Rev 22: 485-518, 1970.

30. Wu D, Zou C, Yue F, Li X, Li S and Zhang YA: The effect of long-term streptozotocin-induced diabetes mellitus (STZ-DM) on cynomolgus (Macaca fascicularis) monkeys. J Med Primatol 38: 15-22, 2009.

31. Sugioka N, Sato K, Haraya K, et al: Effect of streptozotocininduced diabetes mellitus on the pharmacokinetics of nelfinavir in rats. Biopharm Drug Dispos 29: 469-479, 2008.

32. Li M, Inaba M, Guo KQ, Hisha H, Abraham NG and Ikehara S: Treatment of streptozotocin-induced diabetes mellitus in mice by intra-bone marrow bone marrow transplantation plus portal vein injection of beta cells induced from bone marrow cells. Int J Hematol 86: 438-445, 2007.

33. Hartoft-Nielsen ML, Rasmussen AK, Bock T, Feldt-Rasmussen U, Kaas A and Buschard K: Iodine and tri-iodo-thyronine reduce the incidence of type 1 diabetes mellitus in the autoimmune prone BB rats. Autoimmunity 42: 131-138, 2009.

34. Tirabassi RS, Flanagan JF, Wu T, Kislauskis EH, Birckbichler PJ and Guberski DL: The BBZDR/Wor rat model for investigating the complications of type 2 diabetes mellitus. ILAR J 45: 292-302, 2004.

35. Zella JB, McCary LC and DeLuca HF: Oral administration of 1,25-dihydroxyvitamin D3 completely protects NOD mice from insulin-dependent diabetes mellitus. Arch Biochem Biophys 417: 77-80, 2003. 
36. Pedotti R, Sanna M, Tsai M, et al: Severe anaphylactic reactions to glutamic acid decarboxylase (GAD) self peptides in NOD mice that spontaneously develop autoimmune type 1 diabetes mellitus. BMC Immunol 4: 2, 2003.

37. Corsetti JP, Sparks JD, Peterson RG, Smith RL and Sparks CE: Effect of dietary fat on the development of non-insulin dependent diabetes mellitus in obese Zucker diabetic fatty male and female rats. Atherosclerosis 148: 231-241, 2000.

38. Burgdorf C, Hansel L, Heidbreder M, et al: Suppression of cardiac phosphatidate phosphohydrolase 1 activity and lipin mRNA expression in Zucker diabetic fatty rats and humans with type 2 diabetes mellitus. Biochem Biophys Res Commun 390: $165-170,2009$.

39. Bajotto G, Murakami T, Nagasaki M, Sato Y and Shimomura Y: Decreased enzyme activity and contents of hepatic branchedchain alpha-keto acid dehydrogenase complex subunits in a rat model for type 2 diabetes mellitus. Metabolism 58: 1489-1495, 2009.
40. Noguchi S, Ohno Y and Aoki N: Adrenocortical insufficiency in Otsuka Long-Evans Tokushima Fatty rats, a type 2 diabetes mellitus model. Metabolism 56: 1326-1333, 2007.

41. Howarth FC, Shafiullah M and Qureshi MA: Chronic effects of type 2 diabetes mellitus on cardiac muscle contraction in the Goto-Kakizaki rat. Exp Physiol 92: 1029-1036, 2007.

42. Phillips AO, Baboolal K, Riley S, et al: Association of prolonged hyperglycemia with glomerular hypertrophy and renal basement membrane thickening in the Goto Kakizaki model of non-insulindependent diabetes mellitus. Am J Kidney Dis 37: 400-410, 2001.

43. Mauvais-Jarvis F and Kahn CR: Understanding the pathogenesis and treatment of insulin resistance and type 2 diabetes mellitus: what can we learn from transgenic and knockout mice? Diabetes Metab 26: 433-448, 2000.

44. Ristow M: Neurodegenerative disorders associated with diabetes mellitus. J Mol Med (Berl) 82: 510-529, 2004. 